\title{
Molecular epidemiology of Chinese Han deaf patients with bi-allelic and mono- allelic GJB2 mutations
}

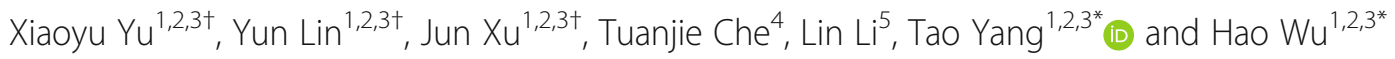

\begin{abstract}
Background: Recessive mutations in GJB2 is the most common cause of genetic hearing loss worldwide. The aim of this study is to determine the spectrum and frequency of GJB2 variants in Chinese Han deaf patients and to investigate the underlying causative genes in patients with mono-allelic GJB2 mutations.

Methods: We analyzed the mutation screening results of GJB2 in 1852 Chinese Han probands with apparently autosomal-recessive hearing loss in our laboratory. Targeted next-generation sequencing of 139 known deafnessrelated genes were performed in 44 probands with mono-allelic GJB2 mutations.

Results: Bi-allelic GJB2 mutations was identified in $25.65 \%$ of patients, in which the c.235delC (p.L79Cfs*3) mutation is the most frequent cause for both severe-to-profound (84.93\%) and mild-to-moderate hearing loss (54.05\%), while the c.109G > A (p.V37l) mutation is another frequent cause for mild-to-moderate hearing loss (40.54\%). In 3.89\% of patients only one mutant allele can be identified in GJB2. Targeted next generation sequencing in 44 such probands revealed digenic heterozygous mutations in GJB2/GJB6 and GJB2/GJB3 as the likely pathogenic mechanism in three probands. In 13 probands, on the other hand, pathogenic mutations in other deafness-associated genes (STRC, EYA1, MITF, PCDH15, USH2A, MYO15A, CDH23, OTOF, SLC26A4, SMPX, and TIMM8A) can be identified as the independent genetic cause, suggesting that the mono-allelic GJB2 mutations in those probands is likely co-incidental.
\end{abstract}

Conclusions: Our results demonstrated that GJB2 should be a primary target for mutation screening in Chinese Han deaf patients, and those with mono-allelic GJB2 mutations should be further screened by next generation sequencing.

Keywords: Hearing loss, GJB2, Mutation screening, Epidemiology, Next generation sequencing

\section{Introduction}

Hearing loss is a heterogeneous disorder that affects language acquisition and social skill development in children. It is estimated that $50 \% \sim 60 \%$ cases of hearing loss have a genetic etiology [1]. To date, there have been over 100 genes identified to cause non-syndromic hearing loss and over 700 genetic syndromes described with features of hearing loss. Despite this, mutations in a single gene GJB2 (OMIM 121011) account for a large proportion of nonsyndromic hearing loss in most populations worldwide [2].

\footnotetext{
* Correspondence: taoyang@sh-jei.org; haowu@sh-jei.org

${ }^{\dagger}$ Xiaoyu Yu, Yun Lin and Jun Xu contributed equally to this work.

'Department of Otorhinolaryngology-Head and Neck Surgery, Shanghai Ninth People's Hospital, Shanghai Jiao Tong University School of Medicine, Shanghai, China

Full list of author information is available at the end of the article
}

The GJB2 gene codes for a gap junction protein connexin-26 (Cx26), which is essential for the physiological function of supporting cells in the cochlea [3]. About 200 GJB2 pathogenic mutations have been reported so far [4]. A number of missense mutations may lead to autosomal dominant non-syndromic hearing loss DFNA3 and autosomal dominant syndromic hearing loss associated with hyperproliferative epidermal disorders $[5,6]$. On the other hand, a majority of GJB2 mutations are inherited in a recessive form and lead to non-syndromic hearing loss DFNB1. The mutation spectrum of GJB2 and the frequencies of these mutations vary greatly across different ethnic groups $[2,7]$, and the Chinese population has a quite distinct spectrum of GJB2 mutations from other populations [8]. With China having approximately one fifth of the world's population, evaluating the molecular epidemiology of GJB2

(c) The Author(s). 2020 Open Access This article is distributed under the terms of the Creative Commons Attribution 4.0 International License (http://creativecommons.org/licenses/by/4.0/), which permits unrestricted use, distribution, and 
mutations in Chinese deaf patients has important implications in guiding genetic testing for deafness. In the present study, we analyzed the GJB2 mutation screening results and audiometric data of 1852 Chinese Han deaf probands to determine its GJB2 mutation spectrum and genotypephenotype correlation.

In addition, previous mutation screening of GJB2 in deaf patients revealed that a substantial number of them carried only one mutant allele $[2,9,10]$. The allele frequency of GJB2 mutations in heterozygous patients was significantly higher than expected in the general population. Possibly other mutations, either within the DFNB1 locus or in other unlinked genes, could contribute to the hearing loss in patients with mono-allelic GJB2 mutations. To this end, this study also used targeted next-generation sequencing (NGS) to detect single nucleotide variants, small insertions and deletions (indels) and copy number variations (CNVs) of 139 known deafness-related genes in 44 patients with mono-allelic GJB2 mutations. The results would provide important information for genetic testing and counselling, especially for those with mono-allelic GJB2 mutations.

\section{Materials and methods}

\section{Patients}

We reviewed the records of patients with sensorineural hearing loss who received genetic testing for deafness in our laboratory in Shanghai Ninth People's Hospital, Shanghai Jiao Tong University School of Medicine. Included in this study were patients with bilateral, non-syndromic, sensorineural hearing loss. A total of 1852 unrelated deaf probands, 979 males and 873 females, were analyzed for GJB2 testing and audiological examination results. The familial cases were compatible with an autosomal-recessive inheritance and the rest cases were sporadic. The ages of the subjects ranged from 2 months to 68 years, with the median age of 12 years old. All subjects were of Chinese Han ethnicity. The severity of hearing loss was classified based on the better hearing ear as mild $(21 \sim 40 \mathrm{~dB})$, moderate (41 70 dB), severe (71 95 dB), and profound (> $95 \mathrm{~dB})$.

\section{Ethics statement}

A written informed consent was obtained from each subject or their guardians to participate in this study. This study was approved by the Ethics Committee of Shanghai Ninth People's Hospital, Shanghai Jiao Tong University School of Medicine.

\section{Mutation analysis of the GJB2 gene}

Genomic DNA was extracted from blood samples using the Genomic DNA Extraction Kit (Tiangen Biotech, Beijing, China). The GJB2 (NM_004004.5) coding exon (exon 2) and flanking regions as well as the non-coding exon 1 and its flanking splice sites were amplified by polymerase chain reaction (PCR), and the PCR product was then Sanger sequenced in both directions. Sequence data were analyzed using Sequencher 5.4.5, and primer sequences are provided in Additional file 1: Table S4.

\section{Targeted next-generation sequencing}

For library preparation, $2 \mu \mathrm{g}$ genomic DNA was randomly fragmented to $150-200 \mathrm{bp}$ fragments by ultrasound shearing. End-repair, adenylation, adapter ligation and PCR amplification were completed according to the standard Illumina protocol. The amplified DNA was captured with a Deafness-related Gene Panel (WuXi NextCODE, Shanghai, China) designed to capture all exons and splicing sites of 139 deafness genes. Sequencing of the enrichment libraries were then performed on the Illumina HiSeq high-throughput platform.

The raw reads were mapped to the human reference genome (UCSC hg19), and the Sentieon software suite was used to call Single Nucleotide Variants (SNVs) and small insertions or deletions (InDels). Copy number variation detection was carried out with CNVkit [11] and ExomeDepth [12] tools that detect copy number variations based on read depth. The SNVs and InDels were annotated with an inhouse developed annotation pipeline developed by WuXi NextCODE using Variant Effect Predictor (VEP) software.

\section{Variant filtering and interpretation}

With the exception of three known common mutations in Chinese Hans, c.235delC and c.109G > A in GJB2 and c.919$2 \mathrm{~A}>\mathrm{G}$ in SLC26A4, an in-house Chinese Han allele frequency database was used to exclude variants with minor mutation frequency (MAF) higher than 0.005 in the general population. ClinVar, OMIM and HGMD database were used to annotate known pathogenic variants. In addition, multiple computational tools (SIFT, Polyphen2, PROVEAN, MutationTaster and PANTHER) were used to predict the functionality of nonsynonymous variants. Segregation analysis was performed when DNA samples from the family members were available. The reported variants and CNVs were validated by Sanger sequencing (primer sequences for PCR amplification are provided in Additional file 1: Table S4).

\section{Results}

\section{Spectrum and genotype-phenotype correlation of GJB2} mutations

Sanger sequencing of both the coding and noncoding exon and flanking sites of GJB2 in 1852 Chinese Han deaf probands identified a total of 47 different mutations. The most frequent variants included four frameshift mutations c.235delC (p.L79Cfs*3, allele frequency 18.25\%, 676/3704), c.299_300delAT (p.H100Rfs*14, 2.94\%), c.507insAACG (p.A171Efs*40, 0.65\%), c.36insG (p.V13Cfs*35, 0.24\%) and three missense mutations c.109G $>$ A (p.V37I, 7.88\%), c. $368 \mathrm{C}>\mathrm{A}$ (p.T123 N, 0.84\%) and c.257C > G (p.T86R, $0.51 \%$ ) (Table 1 ). In addition, four dominant mutations 
Table 1 Pathogenic or unclassified variants in GJB2 among 1852 deaf patients

\begin{tabular}{|c|c|c|c|c|}
\hline Nucleotide Change & Effect on Protein & Allele counts & Allele Frequency in 1852 deaf patients (\%,3704 allele) & Category \\
\hline \multicolumn{5}{|l|}{ Frameshift mutations } \\
\hline c.235delC & frameshift & 676 & 18.25 & pathogenic \\
\hline c.299_300delAT & frameshift & 109 & 2.94 & pathogenic \\
\hline c.507insAACG & frameshift & 24 & 0.65 & pathogenic \\
\hline c.36insG & frameshift & 9 & 0.24 & pathogenic \\
\hline c.176del16bp & frameshift & 7 & 0.19 & pathogenic \\
\hline c.605ins 46 & frameshift & 7 & 0.19 & pathogenic \\
\hline c.312del14 & frameshift & 1 & 0.03 & pathogenic \\
\hline c.35delG & frameshift & 1 & 0.03 & pathogenic \\
\hline c.443delC & frameshift & 1 & 0.03 & pathogenic \\
\hline c.493insG & frameshift & 1 & 0.03 & pathogenic \\
\hline Nonsense mutation & & & 0.00 & \\
\hline$c .9 \mathrm{G}>\mathrm{A}$ & p. W3* & 4 & 0.11 & pathogenic \\
\hline C. $139 \mathrm{G}>\mathrm{T}$ & p. E47* & 5 & 0.13 & pathogenic \\
\hline$c .231 G>A$ & p. W77* & 2 & 0.05 & pathogenic \\
\hline Missense mutations & & & 0.00 & \\
\hline c. $109 \mathrm{G}>\mathrm{A}$ & p. V371 & 292 & 7.88 & Pathogenic $^{a}$ \\
\hline C. $368 C>A$ & p. T123 N & 31 & 0.84 & unclassified \\
\hline c. $257 C>$ G & p. T86R & 19 & 0.51 & pathogenic \\
\hline c. $427 \mathrm{C}>\mathrm{T}$ & p. R143W & 7 & 0.19 & pathogenic \\
\hline $\mathrm{C} .571 \mathrm{~T}>\mathrm{C}$ & p. F191 L & 5 & 0.13 & unclassified \\
\hline c. $344 \mathrm{~T}>\mathrm{G}$ & p. F115C & 4 & 0.11 & unclassified \\
\hline c. $11 \mathrm{G}>\mathrm{A}$ & p. G4D & 3 & 0.08 & pathogenic \\
\hline c. $224 \mathrm{G}>\mathrm{A}$ & p. R75Q & 3 & 0.08 & pathogenic \\
\hline c. $223 \mathrm{C}>\mathrm{T}$ & p. R75W & 2 & 0.05 & pathogenic \\
\hline c.389G > T & p. G130 V & 2 & 0.05 & pathogenic \\
\hline c. $583 \mathrm{~A}>\mathrm{G}$ & p. M195 V & 2 & 0.05 & unclassified \\
\hline C. $164 C>A$ & p. $755 \mathrm{~N}$ & 1 & 0.03 & pathogenic \\
\hline c. $181 \mathrm{~A}>\mathrm{C}$ & p. K61Q & 1 & 0.03 & pathogenic \\
\hline c. $187 \mathrm{G}>\mathrm{T}$ & p. V63 L & 1 & 0.03 & pathogenic \\
\hline $\mathrm{c} .77 \mathrm{C}>\mathrm{T}$ & p. T26l & 1 & 0.03 & unclassified \\
\hline c. $95 \mathrm{G}>\mathrm{A}$ & p. $\mathrm{R} 32 \mathrm{H}$ & 1 & 0.03 & pathogenic \\
\hline c. $232 \mathrm{G}>\mathrm{A}$ & p. A78T & 1 & 0.03 & unclassified \\
\hline$c .242 \mathrm{~T}>\mathrm{G}$ & p. L81R & 1 & 0.03 & pathogenic \\
\hline c. $250 \mathrm{G}>\mathrm{A}$ & p. V84 M & 1 & 0.03 & pathogenic \\
\hline$c .253 \mathrm{~T}>\mathrm{C}$ & p. S85P & 1 & 0.03 & pathogenic \\
\hline c. $257 \mathrm{C}>\mathrm{T}$ & p. T86 M & 1 & 0.03 & pathogenic \\
\hline c. $379 \mathrm{C}>\mathrm{T}$ & p. R127C & 1 & 0.03 & pathogenic \\
\hline c. $389 G>C$ & p. G130A & 1 & 0.03 & pathogenic \\
\hline c. $107 \mathrm{~T}>\mathrm{C}$ & p. L36P & 1 & 0.03 & unclassified \\
\hline c.398G >C & p. W133S & 1 & 0.03 & unclassified \\
\hline$c .457 \mathrm{G}>\mathrm{A}$ & p. V153| & 1 & 0.03 & unclassified \\
\hline$c .478 G>A$ & p. G160S & 1 & 0.03 & unclassified \\
\hline c. $493 \mathrm{C}>\mathrm{T}$ & p. R165W & 1 & 0.03 & pathogenic \\
\hline
\end{tabular}


Table 1 Pathogenic or unclassified variants in GJB2 among 1852 deaf patients (Continued)

\begin{tabular}{cllll}
\hline Nucleotide Change & Effect on Protein & Allele counts & Allele Frequency in 1852 deaf patients (\%,3704 allele) & Category \\
\hline c.551G $>$ A & p. R184Q & 1 & 0.03 & pathogenic \\
C.551G $>$ C & p. R184P & 1 & 0.03 & pathogenic \\
C.586A $>$ G & p. I196V & 1 & 0.03 & unclassified \\
C.587 T > C & p. I196T & 1 & 0.03 & unclassified \\
C.598G > A & p. G200R & 1 & 0.03 & pathogenic \\
Splice site mutation & & & & pathogenic \\
C.-3170G > A & IVS1 + 1 G > A & 1 & 0.03 &
\end{tabular}

${ }^{a}$ The p.V37I variant is a pathogenic variant with variable expressivity and incomplete penetrance [13]

c.164C > A (p. T55 N), c.224G > A (p. R75Q), c.223C > T (p. R75W) and c.551G > A (p. R184Q) were identified in seven subjects and fourteen unclassified variants were detected in 51 subjects (Additional file 1: Tables S1\&S3).

Overall, bi-allelic (homozygous and compound heterozygous) pathogenic mutations in GJB2 were identified in 475 probands (25.65\%, Table 2). Among them, c.235delC/c.23 5delC (227, 47.79\%), c.109G > A/c.109G > A (53, 11.16\%), c.235delC/c.299_300delAT (86, 18.11\%), c.235delC/c.109 G > A (20, 4.21\%), c.235delC/c.507insAACG (18, 3.79\%) and c.235delC/c.257C > G (11, 2.32\%) were the most common pathogenic GJB2 genotypes. These six common genotypes were found in up to $87.37 \%$ probands with bi-allelic GJB2 mutations in our cohort (Table 2).

When analyzing the hearing loss levels in these subjects, we found that $92.21 \%(438 / 475)$ of patients with bi-allelic GJB2 mutations exhibited severe-to-profound hearing loss (Table 2). The c.235delC mutation alone, was identified in $372(84.93 \%)$ such probands in at least one allele. On the contrary, the c.235delC and c.109G > A mutations are the major causes for the remaining 37 probands with mild-to-moderate hearing loss, accounting for $54.05 \%(20 / 37)$ and $40.54 \%$ (15/ 37) of probands in at least one allele, respectively.

\section{Additional or alternative causes in patients with mono- allelic GJB2 mutations}

In our cohort, we also found 72 (3.89\%) deaf probands carrying only a single recessive pathogenic mutation of GJB2 (Additional file 1: Table S1, the heterozygous c.109G $>$ A variant is not included in this group due to its incomplete penetrance and high frequency in the general population of Chinese Hans [13]). To elucidate the molecular etiology of the hearing loss in probands with mono-allelic GJB2 mutations, we further sequenced 139 known deafnessrelated genes (Additional file 1: Table S2) by targeted NGS in 44 such probands with good quality and quantity of DNA samples.
Despite that genomic deletions containing GJB6 and upstream regions of GJB2 was frequently detected in several ethnic groups [14, 15], such genomic deletion was not detected in our $\mathrm{CNV}$ analysis based on read depth of the NGS. Instead, in three probands (D592, C290 and D1028) with mono-allelic c.235delC mutation in GJB2, we identified an additional heterozygous mutation c.538C $>\mathrm{T}$ (p. R180*) in GJB3, c.547G > A (p.E183K) in GJB3 and c.228delG (p. L79Cfs*3) in GJB6, respectively (Table 3). These GJB2/GJB3 and GJB2/ GJB6 mutations may combine to cause hearing loss in a digenic inheritance pattern as previously reported $[15,16]$.

Our targeted NGS also identified a variety of independent pathogenic mutations in 13 (29.55\%) probands (Table 3, Additional file 1: Table S3), indicating that they were simply coincidental carriers of the GJB2 mutations. Among them, probands D908 and D2002 were found to carry homozygous deletions of the entire STRC gene (Additional file 1: Figure S1) and proband D1857 has a heterozygous deletion and a nonsense mutation c.3696G > A (p. W1232*) in STRC. Consistent with previous studies [17], all three probands with STRC homozygous or compound heterozygous deletions have moderate hearing loss (PTAs of 40-50 dB HL). Fourteen of the sixteen other independent mutations identified in this study have been reported to be associated with hearing loss in previous studies, including dominant mutations EYA1 c.1276G > A (p. G426S) [18] and MITF c.877C > T (p. R293*) [19], recessive mutations $P C D H 15$ c.4133C $>$ T (p. T1378I) and c.1453delT (p. S485Rfs*2) [20], USH2A c.10904C > A (p.T3635 N) [21], MYO15A c.8158G > A (p. D2720N) and c.10258_10260delTTC (p.F3420-) [22], CDH23 c.7630 T > G (p. L2544 V) and c.8257G > A (p.A2753T) [20], OTOF c.2122C > T (p.R708*) and c.1194 T > A (p.D398E) [23, 24], SLC26A4 c.1174A > T (p. N392Y) and c.1975G > C (p.V659 L) [25], and SMPX c.55A > G (p. N19D) [26]. One novel hemizygous mutation, c.201delT (p.E68Sfs"11) in TIMM8A, was identified in a male proband D211 as a likely pathogenic mutation since similar 
Table 2 Genotypes and phenotypes of 475 deaf probands with bi-allelic GJB2 mutations

\begin{tabular}{|c|c|c|c|c|c|}
\hline \multirow[t]{2}{*}{ Genotype } & \multicolumn{4}{|c|}{ Severity of Hearing Loss } & \multirow[t]{2}{*}{ Total } \\
\hline & Mild & Moderate & Severe & Profound & \\
\hline c.235delC /c.235delC & 0 & 11 & 77 & 139 & 227 \\
\hline c.109G > A /c.109G > A & 7 & 8 & 20 & 18 & 53 \\
\hline c.299_300delAT/c.299_300delAT & 0 & 0 & 3 & 0 & 3 \\
\hline c.507insAACG /c.507insAACG & 0 & 0 & 1 & 0 & 1 \\
\hline c.235delC /c.299_300delAT & 0 & 2 & 34 & 50 & 86 \\
\hline c.235delC /c.109G > A & 0 & 5 & 6 & 9 & 20 \\
\hline c.235delC /c.507insAACG & 0 & 1 & 7 & 10 & 18 \\
\hline c.235delC /c.257C > G & 0 & 1 & 2 & 8 & 11 \\
\hline c.235delC /c.605ins46 & 0 & 0 & 1 & 4 & 5 \\
\hline c.235delC /c.139G > T & 0 & 0 & 2 & 3 & 5 \\
\hline c.235delC /c.9G > A & 0 & 0 & 1 & 2 & 3 \\
\hline c.235delC /c.427C > T & 0 & 0 & 1 & 2 & 3 \\
\hline c.235delC /c.36insG & 0 & 0 & 0 & 3 & 3 \\
\hline c.235delC /c.598G > A & 0 & 0 & 0 & 2 & 2 \\
\hline c.299_300delAT /c.176del16bp & 0 & 1 & 0 & 1 & 2 \\
\hline c. $257 \mathrm{C}>\mathrm{G} / \mathrm{c} .507 \mathrm{ins} A A C G$ & 0 & 0 & 0 & 2 & 2 \\
\hline c.36insG /c.176del16bp & 0 & 0 & 0 & 2 & 2 \\
\hline c.235delC /c.223C > T & 0 & 0 & 1 & 0 & 1 \\
\hline c.235delC /c.231G > A & 0 & 0 & 0 & 1 & 1 \\
\hline c.235delC /c.242T> G & 0 & 0 & 1 & 0 & 1 \\
\hline c.235delC /c.257C > T & 0 & 0 & 0 & 1 & 1 \\
\hline c.235delC /c.389G > C & 0 & 0 & 1 & 0 & 1 \\
\hline c.235delC /c.35delG & 0 & 0 & 0 & 1 & 1 \\
\hline c.235delC /c.176del16bp & 0 & 0 & 0 & 1 & 1 \\
\hline c.235delC /c.312del14 & 0 & 0 & 1 & 0 & 1 \\
\hline c.235delC /c.11G > A & 0 & 0 & 1 & 0 & 1 \\
\hline c.299_300delAT /c.-3170G > A & 0 & 0 & 1 & 0 & 1 \\
\hline c.299_300delAT /c.257C > G & 0 & 0 & 0 & 1 & 1 \\
\hline c.299_300delAT /c.427C > T & 0 & 0 & 0 & 1 & 1 \\
\hline c.299_300delAT /c.443delC & 0 & 1 & 0 & 0 & 1 \\
\hline c.299_300delAT /c.605ins46 & 0 & 0 & 1 & 0 & 1 \\
\hline c.36insG /c.109G > A & 0 & 0 & 1 & 0 & 1 \\
\hline c.36insG /c.427C > T & 0 & 0 & 1 & 0 & 1 \\
\hline c.36insG /c.507insAACG & 0 & 0 & 0 & 1 & 1 \\
\hline$c .9 G>A / c .231 G>A$ & 0 & 0 & 1 & 0 & 1 \\
\hline c.257C > G /c.493insG & 0 & 0 & 0 & 1 & 1 \\
\hline c.257C > G /c.299_300delAT & 0 & 0 & 0 & 1 & 1 \\
\hline c. $379 \mathrm{C}>\mathrm{T} / \mathrm{c} .478 \mathrm{G}>\mathrm{A}$ & 0 & 0 & 0 & 1 & 1 \\
\hline c.109G > A /c.605ins46 & 0 & 0 & 1 & 0 & 1 \\
\hline c.109G > A /c.299_300delAT & 0 & 0 & 0 & 1 & 1 \\
\hline c.109G > A /C.181A >C & 0 & 0 & 1 & 0 & 1 \\
\hline c. $109 \mathrm{G}>\mathrm{A} / \mathrm{c} .250 \mathrm{G}>\mathrm{A}$ & 0 & 0 & 1 & 0 & 1 \\
\hline c. $109 \mathrm{G}>\mathrm{A} / \mathrm{c} .257 \mathrm{C}>\mathrm{G}$ & 0 & 0 & 1 & 0 & 1 \\
\hline
\end{tabular}


Table 2 Genotypes and phenotypes of 475 deaf probands with bi-allelic GJB2 mutations (Continued)

\begin{tabular}{|c|c|c|c|c|c|}
\hline \multirow[t]{2}{*}{ Genotype } & \multicolumn{4}{|c|}{ Severity of Hearing Loss } & \multirow[t]{2}{*}{ Tota } \\
\hline & Mild & Moderate & Severe & Profound & \\
\hline c.109G > A / c.427C > T & 0 & 0 & 1 & 0 & 1 \\
\hline c.176del16bp /c.389G > T & 0 & 0 & 0 & 1 & 1 \\
\hline c.176del16bp /c. 95G > A & 0 & 0 & 0 & 1 & 1 \\
\hline Total & 7 & 30 & 170 & 268 & 475 \\
\hline
\end{tabular}

truncating mutations p.E24* and p.R80* in TIMM8A have been reported to cause hearing loss associated with MohrTranebjaerg syndrome [27]. The novel c.392A > G (p.N131S) in $U S H 2 A$ identified in compound heterozygosity with the known c.10904C > A (p.T3635 N) mutation is a variant of uncertain significance (VUS).

Based on the new genetic diagnosis, we revisited the clinical aspects of proband D289 and D554. Proband D289 with SLC26A4 c.1174A > T (p. N392Y) and c.1975G > C (p.V659 L) mutations had profound hearing loss and bilateral enlarged vestibular aqueduct, which is characteristic of biallelic SLC26A4 mutations. Proband D554 with USH2A c.10904C > A (p.T3635 N) and c.392A > G (p.N131S) mutations was two years old and had no signs of retinitis pigmentosa so far. As retinitis pigmentosa may develop after puberty for patients with $U S H 2 A$ mutations, we recommended that visual acuity and visual fields of the patient be monitored by an ophthalmologist at older age.

\section{Discussion}

In this study, we presented an overview on the mutation spectrum of GJB2 in a large cohort $(n=1852)$ of patients with hearing loss in Chinese Hans. Biallelic mutations in GJB2 are responsible for up to $25.65 \%$ of patients, representing the most frequent cause for genetic hearing loss in our cohort. The most prevalent GJB2 mutations identified in this study were c.235delC and c.109G > A, accounting for 65.16 and $11.79 \%$ of the mutant alleles. Most (92.21\%) of the patients with bi-allelic GJB2 mutations had severe-to-profound hearing loss, in which the c. $235 \mathrm{delC}$ is the predominant causes (84.93\%). Interestingly, our results showed that c. $235 \mathrm{delC}$ also contributes to mild-to-moderate hearing loss in a significant percentage $(54.05 \%)$ of such patients, with c.109G > A being another major contributor (40.54\%, Table 2). In comparison with previous studies of other Chinese ethnicities such as the Uyghur population [28], the mutation spectrum of GJB2 is considerably different in Chinese Hans, as c.35delG, a common GJB2 mutation in both Uyghurs and
Caucasians, was detected in only one proband in our cohort.

It has long been puzzling that mutation screening of GJB2 in a large proportion (6-15\%) of patients with autosomal recessive hearing loss would identify only one pathogenic mutant allele [9, 29, 30]. In our cohort, we also identified 72 (3.89\%) subjects carrying only a single recessive pathogenic mutation in GJB2, and that excludes those carrying the incompletely penetrant c.109G $>$ A variant, which has a carrier frequency of $12.2 \%$ in Chinese Han normal hearing controls [31]. In our cohort, the carrier rate of mono-allelic mutations in GJB2 $(3.89 \%$ overall, $2.97 \%$ for c.235delC) is higher than that previously reported in the Chinese Han general population (2.45\% overall, $1.78 \%$ for c.235delC) [32], suggesting that at least in some cases a second unidentified pathogenic mutation may act either in cis or in trans to the GJB2 mutation to lead to the hearing loss. This hypothesis has subsequently been proved by our targeted NGS in 44 probands with mono-allelic GJB2 mutations. In three probands, digenic inheritance of GJB2/GJB3 and GJB2/GJB6 mutations was identified as the likely pathogenic cause for their hearing loss (Table 3). On the other hand, two dominant and a series of recessive mutations in 11 deafness-associated genes were also identified as the independent pathogenic causes in 13 additional probands, suggesting that those probands are coincidental carriers of the GJB2 mutations.

Overall our targeted NGS resolved the pathogenic cause in $16(36.36 \%)$ probands with mono-allelic GJB2 mutations, validating the importance of highthroughput sequencing in such patients. For the remaining unresolved cases, possible pathogenic causes may include: 1) a second mutant allele in GJB2 may exist deeply in the introns or the noncoding regulatory regions uncovered by the targeted NGS; 2) mutation in a yet unknown deafnessassociated gene may lead to the hearing loss in coordination with or independent to the GJB2 mutation; and 3) in some sporadic cases environmental factors may contribute to the hearing loss. 
Table 3 Pathogenic mutations identified by targeted NGS in probands with GJB2 mono-allelic mutations

\begin{tabular}{|c|c|c|c|c|c|c|c|}
\hline $\begin{array}{l}\text { Patient } \\
\text { ID }\end{array}$ & Gene $^{a}$ & Type of variation & Nucleotide change & $\begin{array}{l}\text { Amino acid } \\
\text { change }\end{array}$ & Zygosity & $\begin{array}{l}\text { Segregating with } \\
\mathrm{HL}^{\mathrm{b}}\end{array}$ & $\begin{array}{l}\text { The GJB2 mutant } \\
\text { allele }\end{array}$ \\
\hline \multirow[t]{2}{*}{ D592 } & GJB2 & Frameshift indel & c.235delC & p. L79Cfs*3 & het & ND & c.235delC \\
\hline & GJB3 & Stop_gained & $\mathrm{C} .538 \mathrm{C}>\mathrm{T}$ & p. R180* & het & & \\
\hline \multirow[t]{2}{*}{ C290 } & GJB2 & Frameshift indel & c.235delC & p. L79Cfs*3 & het & Yes & c.235delC \\
\hline & GJB3 & Missense & c. $547 \mathrm{G}>\mathrm{A}$ & p. E183K & het & & \\
\hline \multirow[t]{2}{*}{ D1028 } & GJB2 & Frameshift indel & c.235delC & p. L79Cfs*3 & het & Yes & c.235delC \\
\hline & GJB6 & Frameshift indel & c.228delG & p. W77Gfs*5 & het & & \\
\hline \multirow[t]{2}{*}{ D908 } & STRC & $\begin{array}{l}\text { Whole gene } \\
\text { deletion }\end{array}$ & - & - & hom & Yes & c.235delC \\
\hline & STRC & $\begin{array}{l}\text { Whole gene } \\
\text { deletion }\end{array}$ & - & - & hom & & \\
\hline \multirow[t]{2}{*}{ D2002 } & STRC & $\begin{array}{l}\text { Whole gene } \\
\text { deletion }\end{array}$ & - & - & hom & Yes & c.235delC \\
\hline & STRC & $\begin{array}{l}\text { Whole gene } \\
\text { deletion }\end{array}$ & - & - & hom & & \\
\hline \multirow[t]{2}{*}{ D1857 } & STRC & Partial gene deletion & - & - & het & Yes & c.235delC \\
\hline & STRC & Stop_gained & c. $3696 \mathrm{G}>\mathrm{A}$ & p. W1232* & het & & \\
\hline D1807 & EYA1 & Missense & c. $1276 G>A$ & p. G426S & het & De novo & c.235delC \\
\hline D281 & MITF & Stop_gained & c. $877 \mathrm{C}>\mathrm{T}$ & p. R293* & het & De novo & c.299_300delAT \\
\hline \multirow[t]{2}{*}{ D349 } & PCDH15 & Missense & c. $4133 \mathrm{C}>\mathrm{T}$ & p. T1378| & $\begin{array}{l}\text { compound } \\
\text { het }\end{array}$ & Yes & c.235delC \\
\hline & PCDH15 & Frameshift indel & c.1453delT & p. S485Rfs*2 & $\begin{array}{l}\text { compound } \\
\text { het }\end{array}$ & & \\
\hline \multirow[t]{2}{*}{ D554 } & USH2A & Missense & C. $10904 C>A$ & p. T3635 N & $\begin{array}{l}\text { compound } \\
\text { het }\end{array}$ & Yes & c.235delC \\
\hline & USH2A & Missense & c. $392 A>G$ & p. N131S & $\begin{array}{l}\text { compound } \\
\text { het }\end{array}$ & & \\
\hline \multirow[t]{2}{*}{ D822 } & MYO15A & Missense & $c .8158 \mathrm{G}>\mathrm{A}$ & p. D2720N & $\begin{array}{l}\text { compound } \\
\text { het }\end{array}$ & Yes & c.235delC \\
\hline & MYO15A & In-frame del & $\begin{array}{l}\text { c.10258 } \\
\text { 10260delTTC }\end{array}$ & p. F3420- & $\begin{array}{l}\text { compound } \\
\text { het }\end{array}$ & & \\
\hline \multirow[t]{2}{*}{ C649 } & $\mathrm{CDH} 23$ & Missense & c.7630 T > G & p. L2544 V & $\begin{array}{l}\text { compound } \\
\text { het }\end{array}$ & Yes & c.235delC \\
\hline & $\mathrm{CDH} 23$ & Missense & $c .8257 G>A$ & p. A2753T & $\begin{array}{l}\text { compound } \\
\text { het }\end{array}$ & & \\
\hline \multirow[t]{2}{*}{ D463 } & OTOF & Stop_gained & c. $2122 C>T$ & p. R708* & $\begin{array}{l}\text { compound } \\
\text { het }\end{array}$ & Yes & c. $235 \mathrm{delC}$ \\
\hline & OTOF & Missense & c.1194 T>A & p. D398E & $\begin{array}{l}\text { compound } \\
\text { het }\end{array}$ & & \\
\hline \multirow[t]{2}{*}{ D289 } & SLC26A4 & Missense & c. $1174 \mathrm{~A}>\mathrm{T}$ & p. N392Y & $\begin{array}{l}\text { compound } \\
\text { het }\end{array}$ & Yes & c.235delC \\
\hline & & Missense & c.1975G >C & p. V659L & $\begin{array}{l}\text { compound } \\
\text { het }\end{array}$ & & \\
\hline D237 & SMPX & Missense & c. $55 \mathrm{~A}>\mathrm{G}$ & p. N19D & hemi & ND & c.235delC \\
\hline D211 & TIMM8A & Frameshift indel & c.201delT & p. E68Sfs*11 & hemi & ND & c. $235 \mathrm{delC}$ \\
\hline
\end{tabular}

Abbreviations: HL hearing loss, het heterozygous, hom homozygous, hemi hemizygous, ND not determined or not conclusive

${ }^{a}$ The reference sequence transcript IDs for each gene were GJB2 NM_004004.5, GJB3 NM_024009.2, GJB6 NM_006783.4, STRC NM_153700.2, EYA1 NM_000503.5, MITF NM_000248.3, PCDH15 NM_001142771.1, USH2A NM_206933.2, MYO15A NM_016239.3, CDH23 NM_022124.5, OTOF NM_194248.2, SLC26A4 NM_000441.1, SMPX NM 014332.2, TIMM8A NM 004085.3

${ }^{\mathrm{b}}$ Segregating with $\mathrm{HL}$, determined on basis of segregation analysis in affected and/or unaffected family members 


\section{Conclusions}

Our results showed that mutations in GJB2 account for over $25 \%$ of pathogenic causes in Chinese Han deaf patients, with expanded screening in other deafness-associated genes may help to further resolve cases with mono-allelic GJB2 mutations. The sequential Sanger sequencing and targeted next generation sequencing may be an efficient approach for genetic diagnosis of deafness in Chinese Hans.

\section{Supplementary information}

Supplementary information accompanies this paper at https://doi.org/10. 1186/s13023-020-1311-2

Additional file 1: Table S1. Phenotype and GJB2-associated genotypes of 1852 Chinese Han deaf patients. Table S2. 139 deafness-related genes sequenced in the targeted panel. Table S3. Function prediction of missense mutations using multiple computational tools. Table S4. Primers used in this study. Figure S1. Ratio plots showing homozygous deletion of STRC in patient D908, D2002 and heterozygous deletion of STRC in patient D1857

\section{Acknowledgements}

We thank the patients and their families for participating in this study.

\section{Authors' contributions}

Conceptualization, TY and HW; Formal analysis, X-YY and TY; Funding acquisition, TY and HW; Investigation, X-YY, YL and JX; Methodology, T-JC and LL; Project administration, TY and HW; Supervision, HW; Writing - original draft, $X-Y Y$; Writing - review \& editing, TY. All authors read and approved the final manuscript.

\section{Funding}

This research was supported by grants from National Key R\&D Program of China (2017YFC1001804 to HW), Shanghai Municipal Education Commission - Gaofeng Clinical Medicine Grant (20152519 to TY) and Shanghai Municipal Science and Technology Commission (14DZ2260300 to HW).

\section{Availability of data and materials}

The data that support the findings of this study are openly available in SRA database at https://www.ncbi.nlm.nih.gov/sra, reference number PRJNA560673.

\section{Ethics approval and consent to participate}

A written informed consent was obtained from each subject or their guardians to participate in this study. This study was approved by the Ethics Committee of Shanghai Ninth People's Hospital, Shanghai Jiao Tong University School of Medicine.

\section{Consent for publication}

Not applicable.

\section{Competing interests}

The authors declare that they have no competing interests.

\section{Author details}

'Department of Otorhinolaryngology-Head and Neck Surgery, Shanghai Ninth People's Hospital, Shanghai Jiao Tong University School of Medicine, Shanghai, China. ${ }^{2}$ Ear Institute, Shanghai Jiao Tong University School of Medicine, Shanghai, China. ${ }^{3}$ Shanghai Key Laboratory of Translational Medicine on Ear and Nose Diseases, Shanghai, China. ${ }^{4}$ Key Laboratory of Functional Genomic and Molecular Diagnosis of Gansu Province, Lanzhou 730030, China. ${ }^{5}$ Laboratory of Precision Medicine and Translational Medicine, Suzhou Hospital Affiliated to Nanjing Medical University, Suzhou Science and Technology Town Hospital, Suzhou 215153, China.
Received: 24 October 2019 Accepted: 17 January 2020

Published online: 28 January 2020

\section{References}

1. Chang KW. Genetics of hearing loss-Nonsyndromic. Otolaryngol Clin N Am. 2015:48(6):1063-72.

2. Chan DK, Chang KW. GJB2-associated hearing loss: systematic review of worldwide prevalence, genotype, and auditory phenotype. Laryngoscope. 2014:124(2):E34-53.

3. Johnson SL, Ceriani F, Houston O, Polishchuk R, Marcotti W. Connexinmediated signaling in nonsensory cells is crucial for the development of sensory inner hair cells in the mouse cochlea. J Neurosci. 2017;37(2):258-68.

4. Stenson PD, Mort M, Ball EV, Evans K, Hayden M, Heywood S, Hussain M, Phillips AD, Cooper DN. The human gene mutation database: towards a comprehensive repository of inherited mutation data for medical research, genetic diagnosis and next-generation sequencing studies. Hum Genet. 2017:136(6):665-77.

5. Del Castillo FJ, Del Castillo I. DFNB1 Non-syndromic Hearing Impairment: Diversity of Mutations and Associated Phenotypes. Front Mol Neurosci. 2017:10:428.

6. Richard G, Brown N, Ishida-Yamamoto A, Krol A. Expanding the phenotypic Spectrum of Cx26 disorders: Bart-Pumphrey syndrome is caused by a novel missense mutation in GJB2. J Investig Dermatol. 2004;123(5):856.

7. Tsukada K, Nishio S-Y, Hattori M, Usami S-I. Ethnic-specific Spectrum of GJB2 and SLC26A4 mutations: their origin and a literature review. Ann Otol Rhinol Laryngol. 2015;124(1 suppl):61S-76S.

8. Pu D, Yu F, Han B, Liu X, Wang G, Li Q, Yuan Y, Liu X, Huang D, Kang D. GJB2mutation spectrum in 2063 Chinese patients with nonsyndromic hearing impairment. J Transl Med. 2009;7(1):26.

9. Zheng J, Ying Z, Cai Z, Sun D, He Z, Gao Y, Zhang T, Zhu Y, Chen Y, Guan MX. GJB2 mutation Spectrum and genotype-phenotype correlation in 1067 Han Chinese subjects with non-Syndromic hearing loss. PLoS One. 2015; 10(6):e0128691.

10. Hutchin T, Coy N, Conlon H, Telford E, Bromelow K, Blaydon D, Taylor G, Coghill E, Brown S, Trembath R. Assessment of the genetic causes of recessive childhood non-syndromic deafness in the UK - implications for genetic testing. Clin Genet. 2005:68(6):506.

11. Talevich E, Shain AH, Botton T, Bastian BC. CNVkit: Genome-Wide Copy Number Detection and Visualization from Targeted DNA Sequencing. PLoS computational biology. 2016;12(4):e1004873.

12. Plagnol V, Curtis J, Epstein M, Mok KY, Stebbings E, Grigoriadou S, Wood NW, Hambleton S, Burns SO, Thrasher AJ. A robust model for read count data in exome sequencing experiments and implications for copy number variant calling. Bioinformatics. 2012;28(21):2747-54.

13. Shen J, Oza AM, del Castillo I, Duzkale H, Matsunaga T, Pandya A, Kang HP, Mar-Heyming R, Guha S, Moyer K, et al. Consensus interpretation of the $\mathrm{p}$. Met34Thr and p.Val37lle variants in GJB2 by the ClinGen Hearing Loss Expert Panel. Genetics in Medicine. 2019:21(11):2442-2452.

14. Marlin S, Feldmann D, Blons H, Loundon N, Denoyelle F. GJB2 and GJB6 mutations: genotypic and phenotypic correlations in a large cohort of hearing-impaired patients. Arch Otolaryngol Head Neck Surg. 2005;131(6): 481-7.

15. Del Castillo I, Moreno-Pelayo MA, Del Castillo FJ, Brownstein Z, Marlin S, Adina Q, Cockburn DJ, Pandya A, Siemering KR, Chamberlin GP, et al. Prevalence and evolutionary origins of the del(GJB6-D13S1830) mutation in the DFNB1 locus in hearing-impaired subjects: a multicenter study. Am J Hum Genet. 2003;73(6):1452-1458.

16. Liu XZ, Yuan $Y$, Yan D, Ding EH, Ouyang XM, Fei $Y$, Tang $W$, Yuan $H$, Chang $\mathrm{Q}, \mathrm{Du}$ LL. Digenic inheritance of non-syndromic deafness caused by mutations at the gap junction proteins Cx26 and Cx31. Hum Genet. 2009; 125(1):53-62.

17. Yokota $Y$, Moteki H, Nishio S-Y, Yamaguchi T, Wakui K, Kobayashi Y, Ohyama K, Miyazaki H, Matsuoka R, Abe S, et al. Frequency and clinical features of hearing loss caused by STRC deletions. Sci Rep. 2019;9(1):4408.

18. Li Y, Manaligod JM, Weeks DL. EYA1 mutations associated with the branchioâ-otoâ-renal syndrome result in defective otic development in Xenopus laevis. Biol Cell. 2012:102(5):277-92.

19. Jalilian N, Tabatabaiefar MA, Bahrami T, Karbasi G, Bahramian MH, Salimpoor A, Noori-Daloii MR. A novel pathogenic variant in the $\langle\mathrm{b}\rangle\langle\mathrm{i}\rangle \mathrm{MITF}</ \mathrm{i}\rangle\langle/$ $b>$ gene segregating with a unique Spectrum of ocular findings in an 
extended Iranian Waardenburg syndrome kindred. Mol Syndromol. 2017; 8(4):195.

20. Yang T, Wei X, Chai Y, Li L, Wu H. Genetic etiology study of the nonsyndromic deafness in Chinese Hans by targeted next-generation sequencing. Orphanet J Rare Dis. 2013;8(1):85.

21. Maiko M, Takehiko N, Shin-ya N, Naoyuki K, Shin-ichi U, RJA. Targeted Exon Sequencing Successfully Discovers Rare Causative Genes and Clarifies the Molecular Epidemiology of Japanese Deafness Patients. Plos One. 2013;8(8): e71381.

22. Naz S, Imtiaz A, Mujtaba G, Maqsood A, Bashir R, Bukhari I, Khan MR, Ramzan M, Fatima A, Rehman AU. Genetic causes of moderate to severe hearing loss point to modifiers. Clin Genet. 2017;91(4):589-98.

23. Rodríquez-Ballesteros M, Castillo FJD, Martín Y, Moreno-Pelayo MA, Morera C, Prieto F, Marco J, Morant A, Gallo-Terán J, Morales-Angulo C. Auditory neuropathy in patients carrying mutations in the otoferlin gene (OTOF). Hum Mutat. 2010;22(6):451-6.

24. Cindy $B A$, Yan $S$, Yang HM, Li JQ, Liu Q, Ji YB, Liang Z, Rao SQ, Zhao YL, Dominique W. Screening mutations of OTOF gene in Chinese patients with auditory neuropathy, including a familial case of temperature-sensitive auditory neuropathy. BMC Med Genetics. 2010;11(1):79.

25. Huang S, Han D, Yuan Y, Wang G, Kang D, Zhang X, Yan X, Meng X, Dong M, Dai P. Extremely discrepant mutation spectrum of SLC26A4 between Chinese patients with isolated Mondini deformity and enlarged vestibular aqueduct. J Transl Med. 2011;9(1):167.

26. Niu Z, Yong F, Mei L, Jie S, Jiang L. A novel frameshift mutation of SMPX causes a rare form of $X$-linked nonsyndromic hearing loss in a Chinese family. PLoS One. 2017;12(5):e0178384.

27. Ujike H, Tanabe Y, Takehisa Y, Hayabara T, Kuroda S. A family with X-linked dystonia-deafness syndrome with a novel mutation of the DDP gene. Arch Neurol. 2001;58(6):1004-7.

28. Du W, Wang Q, Zhu Y, Wang Y, Guo Y. Associations between GJB2, mitochondrial 125 rRNA, SLC26A4 mutations, and hearing loss among three ethnicities. Biomed Res Int. 2014:2014:746838.

29. Barashkov NA, Pshennikova VG, Posukh OL, Teryutin FM, Fedorova SA. Spectrum and frequency of the GJB2 gene pathogenic variants in a large cohort of patients with hearing impairment living in a subarctic region of Russia (the Sakha Republic). PLoS One. 2016:11(5):e0156300.

30. Kim Y. GJB2 mutations in the Swiss hearing impaired. Ear Hear. 2003; 24(5):440.

31. Chai Y, Chen D, Sun L, Li L, Chen Y, Pang X, Zhang L, Wu H, Yang T. The homozygous p.V37I variant of GJB2 is associated with diverse hearing phenotypes. Clin Genet. 2015;87(4):350-5.

32. Yin A, Liu C, Zhang Y, Wu J, Mai M, Ding H, Yang J, Zhang X. The carrier rate and mutation spectrum of genes associated with hearing loss in South China hearing female population of childbearing age. BMC Med Genetics. 2013;14(1):57.

\section{Publisher's Note}

Springer Nature remains neutral with regard to jurisdictional claims in published maps and institutional affiliations.

Ready to submit your research? Choose BMC and benefit from:

- fast, convenient online submission

- thorough peer review by experienced researchers in your field

- rapid publication on acceptance

- support for research data, including large and complex data types

- gold Open Access which fosters wider collaboration and increased citations

- maximum visibility for your research: over $100 \mathrm{M}$ website views per year

At $\mathrm{BMC}$, research is always in progress.

Learn more biomedcentral.com/submissions 